\title{
Appropriateness of Routine Crossmatch in Elective Caesarean Section for Low Risk Postpartum Hemorrhage Pregnancies
}

Ngamchuen Sripunlom *, Sarwinee Ratchanon and Sirisuk Ouitrakul

Department of Obstetrics and Gynecology, Faculty of Medicine Vajira Hospital, Navamindradhiraj University, Bangkok, Thailand

*Corresponding author: Sripunlom N, Department of Obstetrics and Gynecology, Faculty of Medicine Vajira Hospital, Navamindradhiraj University, Bangkok, Thailand, Tel: +66930268953; E-mail: ngamchuen29@gmail.com

Received date: December 18, 2017; Accepted date: January 19, 2018; Published date: January 26, 2018

Copyright: (C2018 Sripunlom N, et al. This is an open-access article distributed under the terms of the Creative Commons Attribution License, which permits unrestricted use, distribution, and reproduction in any medium, provided the original author and source are credited.

\begin{abstract}
Objective: The objective of this study is to evaluate appropriateness of the blood ordering practice and transfusion for elective caesarean section in low risk postpartum hemorrhage.

Materials and methods: A prospective descriptive study of routine cross-matching for elective caesarean section in low risk postpartum hemorrhage was conducted in Department of Obstetrics and Gynaecology, Faculty of Medicine Vajira Hospital, Navamindradhiraj University, Bangkok, Thailand from 26 July 2016 to 31 March 2017. Data including patient demographics (maternal age, body mass index and gestational age) and operative findings (indications for caesarean section, levels of surgeon, amount of blood loss and blood transfusion, $\mathrm{Hb}$ change at $24 \mathrm{~h}$ after surgery, operation time and fetal weight) were collected. PPH rate and transfusion utilization indices (Crossmatch to Transfusion ratio (C/T ratio), Transfusion probability $(\% \mathrm{~T})$ and Transfusion index $(\mathrm{Ti})$ ) were calculated.
\end{abstract}

Results: From 169 eligible participants, there were 2 cases excluded because of pre-operative undetected placenta adherent. There were five patients having PPH (3\%). From 334 units of packed red cell (PRC) prepared for 167 patients, there were 6 units transfused to 5 patients. Only one patient received 2 units of PRC. Transfusion utilization indices (C/T ratio, \% T, Ti) were $55.67,2.99$ and 0.03 , respectively. Total cost for the cross matching process was 90,180 baht, but the actual transfusion cost was 2,700 baht.

Conclusions: Routine two units of cross matched PRC for elective caesarean section in low risk PPH was seemingly shown inappropriate and over ordering. It led to unnecessary expenses and time consuming.

Keywords: Caesarean section; Blood transfusion; Crossmatch; Blood preparation; Blood typing

\section{Introduction}

Postpartum hemorrhage (PPH) has been a major cause of morbidity and mortality in pregnant women in all parts of the world [1]. Risk factors of $\mathrm{PPH}$ are abnormal placentation (placenta previa, placenta adherent and abruptio placenta), uterine over distension (multifetal pregnancy, polyhydramnios and fetal macrosomia), grand multiparity, having history of $\mathrm{PPH}$, prolong labour, pregnancy with uterine fibroid, receiving tocolytic drugs, delivery by caesarean section and severe anaemia (hemoglobin ( $\mathrm{Hb}$ ) less than $8 \mathrm{~g} / \mathrm{dl}$ ) [1-4]. Because caesarean section itself is one of the risk factors of $\mathrm{PPH}$, it is possible that pregnancies undergoing caesarean section trend to have greater amount of intra-operative blood loss and have higher chance to receive blood transfusion even in the cases who have no other risk factors $[5,6]$.

Decision concerning blood transfusion in the surgical cases depends on many factors: the type of operation, the extent and speed of blood loss and the presence of concomitant clinical conditions (age of the patient, heart disease and respiratory disorders) [7]. As an initial reference, the indications from the British Committee for Standards in Haematology Blood Transfusion Task Force have been proposed. These guidelines report the maximum acceptable request in standard operating conditions and in the presence of good transfusion practice. It is suggested that requested number of units of red cell concentrates should not exceed that of Maximum Surgical Blood Order Schedule (MSBOS). The proposed MSBOS for caesarean section in this recommendation is typing and screening [7]. However, MSBOS in each health care should be adapted to its local reality.

For all low risk PPH pregnancies undergoing elective caesarean section in Department of Obstetrics and Gynaecology, Faculty of Medicine Vajira Hospital, two units of PRC have been routinely preoperative cross-matched. From the observation, our routine is not only different from the standard but also possibly unnecessary and over ordered. In addition, because of the limitation of blood components in blood bank, all blood components should be preserved for necessary cases that need blood transfusion. Therefore, appropriateness of blood preparation for each surgery is important for saving time, expenses, and workloads and also decreases in transmission of infection for the personals during blood preparation. According to all these reasons, this study is to evaluate the appropriateness of the blood ordering practice and transfusion for elective caesarean section in low risk PPH.

\section{Methods and Materials}

The prospective descriptive study was conducted in Department of Obstetrics and Gynecology, Faculty of Medicine Vajira Hospital, Navamindradhiraj University, Bangkok, Thailand from 26 July 2016 to 
31 March 2017. The research protocol received ethical approval from the Vajira Institutional Review Board and Ethical Committee in July 2016.

All pregnancies older than 18 years who underwent elective caesarean section at Department of Obstetrics and Gynaecology, Faculty of Medicine Vajira Hospital, Navamindradhiraj University were recruited. Inclusion criteria were term singleton pregnancy, age older than 18 years and planned elective caesarean section. Exclusion criteria were severe anemia $(\mathrm{Hb}<8 \mathrm{~g} / \mathrm{dl}), \mathrm{Rh}$ negative blood group and having other risk factors of $\mathrm{PPH}$ such as abnormal placentation (placenta previa, placenta adherent and abruptio placenta), uterine overdistension (multifetal pregnancy, polyhydramnios and foetal macrosomia), grand multiparity, having history of $\mathrm{PPH}$, prolong labour, pregnancy with uterine fibroid and receiving tocolytic drugs. Sample size was calculated by using $\mathrm{C} / \mathrm{T}$ ratio from 6-month pilot study at Vajira hospital. Pire value or C/T ratio was 0.098 . With 0.95 of confidence $(\alpha=0.05)$, the calculated sample size by using the following formula was 135 . When $20 \%$ dropout was added, 169 participants were required.

$$
\mathrm{N}=(\mathrm{Z} 2 \alpha / 2 . \pi(1-\pi)) / \mathrm{d} 2
$$

All 169 enrolled participants were taken history, physical examination and ultrasound evaluation determining number of foetus, estimated foetal weight and amniotic fluid measurement. If there was no abnormality detected from the history, normal physical examination, no polyhydramnios and estimated foetal weight less than $4,500 \mathrm{~g}$, the participants were included into the study. There was no one excluded from the study at this step. Each patient received the information about the study. After answering their questions until clear understanding, the written informed consents were obtained. Demographic data including maternal age, body mass index, and gestational age were collected. Pre-operative haemoglobin and haematocrit were performed.

Because all participants were healthy reproductive age without impairment of cardiac and lung functions, only volume and speed of blood loss, signs and symptoms of anaemia as well as levels of haemoglobin and haematocrit at $24 \mathrm{~h}$ post caesarean section were used for blood transfusion decision-making. Intra-operative blood loss was the sum of amount of blood in suction bag and estimated blood volume from all blood-stained swabs. Intra-operative blood transfusion depended on the allowable blood loss that was calculated by anaesthetists. The allowable blood loss (ABL) was calculated by using the following formula $[8,9]$.

Allowable blood loss $(\mathrm{ABL})=[\mathrm{EBV} \times(\mathrm{Hi}-\mathrm{Hf})] / \mathrm{Hi}$

\section{$\mathrm{ABL}=$ Allowable blood loss}

EBV=Estimated Blood Volume=body weight $(\mathrm{kg}) \times$ average blood volume $(\mathrm{ml} / \mathrm{kg})$

Average blood volume $=65 \mathrm{ml} / \mathrm{kg}$ in female adult

\section{$\mathrm{Hi}=$ Initial haemoglobin}

\section{Hf=Final haemoglobin}

Postoperative blood loss was calculated by weighing all sanitary pads used within $24 \mathrm{~h}$. Total amount of blood loss was confirmed by haemoglobin and haematocrit change at $24 \mathrm{~h}$ post caesarean section. Postoperative blood transfusion depended on vital signs, the presence of signs and symptoms of anaemia as well as levels of haemoglobin and haematocrit at $24 \mathrm{~h}$ post caesarean section. Operative findings (indications for caesarean section, levels of surgeon, amount of blood loss and blood transfusion, $\mathrm{Hb}$ change at $24 \mathrm{~h}$ after surgery, operation time and fetal weight) were collected. PPH rate was calculated.

The data were analyzed by intention to treat using the SPSS software version 22. Categorical data were analyzed by using chi-square tests and continuous variables were analyzed by using Student's $t$ tests. Mann-Whitney $U$ tests were used for variables that were not normally distributed. Statistical significance was considered at $\mathrm{P}<0.05$. Transfusion utilization indices including Crossmatch to Transfusion ratio $(\mathrm{C} / \mathrm{T}$ ratio), Transfusion probability $(\% \mathrm{~T})$ and Transfusion index (Ti) were calculated (Fig 1). C/T ratio less than $2 \% \mathrm{~T}$ more than $30 \%$ and Ti more than 0.5 meant appropriate blood preparation (Figure 1) [10-12].

$$
\text { Crossmatch }- \text { to }- \text { transfusion ratio }(C / T \text { ratio })=\frac{\text { number of units crossmatch }}{\text { number of units transfused }}
$$

Transfusion probability $(\% T)=\frac{\text { number of patients transfused } \times 100}{\text { number of patients crossmatch }}$

Transfusion index $\left(T_{i}\right)=\frac{\text { number of units transfused }}{\text { number of patients crossmatch }}$

Figure 1: Formulas of transfusion utilization indices.

\section{Result}

This study was conducted between 26 July 2016 and 31 March 2017. There were 169 low risk PPH pregnancies that underwent elective caesarean section included. There were two cases of pre-operative undetected placenta adherent, but intra-operative known, excluded. From 167 pregnancies, 2 units of PRC for each patient were crossmatched. Pre-operative and $24 \mathrm{~h}$ postoperative $\mathrm{Hb}$ was measured. Indications for caesarean section, levels of surgeon, amount of blood 
loss and blood transfusion, $\mathrm{Hb}$ change at $24 \mathrm{~h}$ after surgery, operation time and fetal weight were recorded. Demographic data and operative findings were shown in tables 1 and 2. There were five patients having $\mathrm{PPH}(3 \%)$ and the cause of PPH was uterine atony. Six units of PRC were transfused into 5 patients. Only one patient received 2 units of PRC.

\begin{tabular}{|l|l|}
\hline Characteristic & Results \\
\hline Age (years), mean \pm SD (range) & $29.33 \pm 5.41(18-43)$ \\
\hline Weight $(\mathrm{kg})$, mean \pm SD (range) & $69.50 \pm 10.03(43-107)$ \\
\hline BMI (kg/m2), mean \pm SD (range) & $23.25 \pm 3.35(15.98-35.24)$ \\
\hline Gestational age (weeks), mean \pm SD (range) & $38.30 \pm 0.81(37-40)$ \\
\hline
\end{tabular}

Table 1: Demographic data $(\mathrm{N}=167)$.

\begin{tabular}{|c|c|}
\hline Operative findings & Results \\
\hline \multicolumn{2}{|l|}{ Indications for caesarean section } \\
\hline Previous C/S, n (\%) & $83(49.7)$ \\
\hline Fetal malpresentation, $\mathrm{n}(\%)$ & $22(13.2)$ \\
\hline CPD, n (\%) & $44(26.3)$ \\
\hline Other, n (\%) & $18(10.8)$ \\
\hline \multicolumn{2}{|l|}{ Level of surgeons } \\
\hline Staff, n (\%) & $44(26.3)$ \\
\hline 1st year resident, $\mathrm{n}(\%)$ & $2(1.2)$ \\
\hline 2nd year resident, $\mathrm{n}(\%)$ & $75(44.9)$ \\
\hline 3rd year resident, $\mathrm{n}(\%)$ & $46(27.5)$ \\
\hline $\mathrm{PPH}, \mathrm{n}(\%)$ & $5(3.0)$ \\
\hline \multicolumn{2}{|l|}{ Transfusion (units) } \\
\hline $0, \mathrm{n}(\%)$ & $162(97.0)$ \\
\hline $1, \mathrm{n}(\%)$ & $4(2.4)$ \\
\hline $2, \mathrm{n}(\%)$ & $1(0.6)$ \\
\hline $\begin{array}{l}\text { Amount of blood loss }(\mathrm{ml}) \text {, mean } \pm \mathrm{SD} \\
\text { (range) }\end{array}$ & $481.20 \pm 232.23(100-2300)$ \\
\hline $\begin{array}{l}\text { Haemoglobin change }(\mathrm{g} / \mathrm{dl}) \text {, mean } \pm \\
\text { SD (range) }\end{array}$ & $0.92 \pm 0.69(0.3-5)$ \\
\hline $\begin{array}{l}\text { Operation time }(\mathrm{min}) \text {, mean } \pm \mathrm{SD} \\
\text { (range) }\end{array}$ & $75.90 \pm 17.70(45-185)$ \\
\hline Fetal weight $(\mathrm{g})$, mean $\pm \mathrm{SD}$ (range) & $3198.48 \pm 342.13(2260-4442)$ \\
\hline
\end{tabular}

Table 2: Operative findings $(\mathrm{N}=167)$.

Transfusion utilization indices were calculated for evaluation the appropriateness of routine cross-match in elective caesarean section for low risk PPH. Crossmatch to Transfusion ratio ( $\mathrm{C} / \mathrm{T}$ ratio), Transfusion probability (\%T) and Transfusion index (Ti) were 55.7, 3\% and 0.03 , respectively as shown in (Table 3 ).
Owning to the regulation of The Comptroller General's Department of Thailand for the cost of typing and screening as well as crossmatching in all government hospitals, the cost of typing and screening in each patient was 240 baht and the cost of cross-matching was 150 baht added up for each unit of PRC. Therefore, the cost of 1 unit of cross-matched PRC was 390 baht and 540 baht for 2 units of crossmatched PRC as shown in table 4. To sum up, total cost of 334 units of cross-matched PRC in the study was 90,180 baht but actual cost of transfusion was only 2,700 baht. Surprisingly, total cost of routinely cross-matching was thirty three times greater than actual cost of transfusion.

\begin{tabular}{|l|l|l|}
\hline $\begin{array}{l}\text { Transfusion utilization } \\
\text { indices }\end{array}$ & Calculated data & $\begin{array}{l}\text { References for } \\
\text { appropriate preparation }\end{array}$ \\
\hline $\begin{array}{l}\text { Crossmatch } \\
\text { Transfusion ratio (C/T } \\
\text { ratio) }\end{array}$ & 55.7 & $<2$ \\
\hline $\begin{array}{l}\text { Transfusion probability } \\
(\% \mathrm{~T})\end{array}$ & $3.00 \%$ & $>30 \%$ \\
\hline Transfusion index (Ti) & 0.03 & $>0.5$ \\
\hline
\end{tabular}

Table 3: Transfusion utilization indices.

\begin{tabular}{|l|l|l|}
\hline Blood preparation & Cost/case (Baht) & $\begin{array}{l}\text { Total cost for 167 cases } \\
\text { (Baht) }\end{array}$ \\
\hline Typing and screening & 240 & 40,080 \\
\hline Routine crossmatch & 390 & 65,130 \\
\hline PRC 1 unit & 540 & 90,180 \\
\hline PRC 2 units & &
\end{tabular}

Table 4: Cost of each blood preparation.

\section{Discussion}

From the result of the study, incidence of PPH needed transfusion was $3 \%$. Only one patient received 2 units of PRC. Transfusion utilization indices including Crossmatch to Transfusion ratio $(\mathrm{C} / \mathrm{T}$ ratio), Transfusion probability $(\% \mathrm{~T})$ and Transfusion index (Ti) were $55.7,3 \%$ and 0.03 , respectively. Comparing to the standard references, routine two units of cross-matched PRC for elective caesarean section in low risk PPH in our department was seemingly shown inappropriate and over ordering. These results were compatible with the results of the previous studies.

In the previous studies, there were various transfusion rates reported. Although improvement in surgical techniques could decrease blood loss and blood transfusion at the time of caesarean section, requirement of blood transfusion was still significant, especially in high risk cases [13]. From total 1056 deliveries, 327 pregnancies (31\%) underwent caesarean section. While total of 654 units of blood were reserved, only 89 units (13.6\%) were transfused. Majority of the patients did not need blood transfusion. $81 \%$ of those were transfused in emergency caesarean section. The most common indications for surgery among those transfused patients were placenta previa ( 9 patients with 21 units of blood) and cephalopelvic disproportion (8 patients with 13 units). There was no calculated $\mathrm{C} / \mathrm{T}$ ratio for proper use of cross-matched reported [14]. Comparing to the present study, it reported higher blood transfusion rate. The participants that were all 
caesarean section cases without classifying as low or high risk $\mathrm{PPH}$ pregnancies might be the reason. However, it still showed that most of the patients did not need blood transfusion.

The retrospective study in Thailand evaluating blood transfusion rate in all operations showed that transfusion rate for 478 caesarean section cases was $3.3 \%$. Caesarean section seemed to use less blood than other operations whereas over cross-matching was ordered [15]. These results were compatible with ours. From 23,486 women underwent caesarean section in the prospective observational study in 19 universities, transfusion rate was $3.2 \%$ in primary caesarean section while the rate was $2.2 \%$ in repeated caesarean section [16]. Moreover, transfusion rate declined significantly from $22 \%$ in 1976 to 4 and $5 \%$ in 1996 and 2006, respectively because of improvement in surgical technique. Most of patients receiving blood transfusion were high risk $\mathrm{PPH}$ pregnancies [13]. Another study in 2,286 women in Thailand informed that $\mathrm{C} / \mathrm{T}$ ratio in caesarean section was 5.7. The incidence of blood transfusion was only $2.6 \%$ of the 2,170 patients who were not cross-matched, thus 868,000 baht of cross-matching expenses was saved [17]. The results including low transfusion rate, high $\mathrm{C} / \mathrm{T}$ ratio and cost saving from decrease in routine cross-match were compatible with those in our study.

Although the previous studies reported retrospective data about transfusion rate in all caesarean section cases without determining the risk of $\mathrm{PPH}$ or classifying the patients in specific groups such as elective or emergency cases and primary or repeated caesarean section [18-20], the results were still similar. Firstly, blood transfusion rate was quite low because of improvement of surgical technique. Secondly, blood transfusion was given mostly in high risk PPH.

This study was a prospective study in low risk PPH undergoing elective caesarean section. Therefore, all data were complete. Moreover, the amount of operative blood loss could be accurately recorded and confirmed by comparing pre- and postoperative $\mathrm{Hb}$ change. It was certain that the incidence of $\mathrm{PPH}$ and transfusion rate were reliable. Furthermore, this was the study in selected group so that the results were quite obvious and could confidently be applied in routinely clinical use.

From this study, we found low incidence of PPH and transfusion rate. Additionally, the total cost of routine cross-matching was thirty three times greater than the actual cost of transfusion. Moreover, according to the recommendation for transfusion of red cells from the British Committee for Standards in Haematology Blood Transfusion Task Force, the proposed MSBOS for caesarean section is typing and screening. With these reasons, the routine 2 units of cross-matched PRC in low risk PPH in our department might be changed, for examples typing and screening without cross-matching or only 1 unit of cross-matched PRC for each case, in order to reduce unnecessary tasks and expenses. However, MSBOS in each health care should be adapted to its local reality. For decreasing cost and unnecessary tasks without compromising the quality of care and safety as a result of the training risk that might affect the patients in our residency training, our departmental agreement preferred routine one unit of crossmatched PRC in low risk PPH. The limitation of the study was a small sample size. For further research, the appropriateness of blood preparation in high risk PPH should be studied.

\section{Conclusion}

Routine two units of cross-matched PRC for elective caesarean section in low risk PPH was seemingly shown inappropriate and over ordering. It led to unnecessary expenses and time consuming.

\section{Acknowledgments}

The author would like to thank all participants in this study and all staff of blood bank, laboratory and Department of Obstetrics and Gynaecology in Vajira Hospital for their support.

This study was supported by our institute's fund for academic purposes. No other external fund was involved in the study.

\section{Disclosure}

There were no conflicts of interest in this work.

\section{References}

1. WHO (2012) WHO Recommendations for the Prevention and Treatment of Postpartum Hemorrhage.

2. Ozumba BC, Ezegwui HU (2006) Blood transfusion and caesarean section in a developing country. J Obstet Gynaecol 26: 746-748.

3. Eyelade OR, Adesina OA, Adewole IF, Adebowale SA (2015) Hemorrhage associated with cesarean delivery: when is transfusion needed? Ann Ib Postgrad Med 13: 29-35.

4. Singh B, Adhikari N, Ghimire S, Dhital S (2013) Post-Operative Drop in Hemoglobin and Need of Blood Transfusion in Caesarean section at Dhulikhel Hospital, Kathmandu University Hospital. Kathmandu Univ Med J 42: 144-146.

5. Ransom SB, Fundaro G, Dombrowski MP (1999) Cost-Effectiveness of routine blood type and screen testing for caesarian section. J Reprod Med 44: 592-594.

6. Ness PM, Rosche ME, Barrasso C, Luff RD, Johnson JW Jr (1981) The efficacy of type and screen to reduce unnecessary cross matches for obstetric patients. Am J Obstet Gynaecol 140: 661-664.

7. Liumbruno G, Bennardello F, Lattanzio A, Piccoli P, Rossetti G (2009) Recommendations for the transfusion of red blood cells. Blood Transfus 7: 49-64.

8. Khan FA, Khan M, Ali A, Chohan U (2006) Estimation of blood loss during Caesarean section: an audit. J Pak Med Assoc 56: 572-575.

9. Eipe N, Ponniah M (2006) Perioperative blood loss assessment - How accurate? Indian J Anaesth 50: 35-38.

10. Kamani AA, McMorland GH, Wadsworth LD (1988) Utilization of red blood cell transfusion in an obstetric setting. Am Obstet Gynaecol 159: 1177-1181.

11. Silverman JA, Barrett J, Callum JL (2004) The appropriateness of red blood cell transfusion in the peripartum patient. Obstet Gynecol 104: 1000-1004.

12. Cousins LM, Teplick FB, Poeltler DM (1996) Pre-cesarean blood bank orders: a safe and less expensive approach. Obstet Gynecol 87: 912-916.

13. Pearson GA, MacKenzie IZ (2014) Blood loss and blood transfusion at caesarean section: a prospective observational study covering 30 years. Eur J Obstet Gynecol Reprod Biol 181: 72-77.

14. Akinola OI, Fabamwo AO, Tayo AO, Rabiu KA, Oshodi YA, et al. (2010) Evaluation of blood reservation and use for caesarean sections in a tertiary maternity unit in south western Nigeria. BMC Pregnancy and Childbirth 10: 57.

15. Mujarin Tiloklurs, Ganokwan Klunklin, Jutharak Yimsabai (2007) Reduction the Cost of Blood Preparation for Transfusion in Surgical Patients by Type and Screen. Buddhachinaraj Med J 24: 48-52. 
Citation: Sripunlom N, Ratchanon S, Ouitrakul S (2018) Appropriateness of Routine Crossmatch in Elective Caesarean Section for Low Risk Postpartum Hemorrhage Pregnancies. Clinics Mother Child Health 15: 283. doi:10.4172/2090-7214.1000283

Page 5 of 5

16. Rouse DJ, MacPherson C, Landon M, Varner MW, Leveno KJ, et al. (2006) Blood transfusion and cesarean delivery. Obstet Gynecol 108: 891-897.

17. Trakulkasamsiri S (2007) Cost reduction of crossmatching by Type and screen protocol in Obstetrics patients at Queen Savang Vadhana Memorial Hospital, Thai Red Cross Society. Bull Chiang Mai Assoc Med Sci 40: 114-117.

18. Larsson C, Saltvedt S, Wiklund I, Pahlen S, Andolf E (2006) Estimation of blood loss after caesarean section and vaginal delivery has low validity with a tendency to exaggeration. Acta Obstetricia et Gynecologica 85: 1448-1452.

19. Ismail S, Siddiqui S, Shafiq F, Ishaq M, Khan S (2014) Blood transfusion in patients having caesarean section: a prospective multicentre observational study of practice in three Pakistan hospitals. Int J Obstet Anesth 23: 253-259.

20. Faponle AF, Makinde ON (2007) Caesarean section: intra-operative blood loss and its restitution. East Afr Med J 84: 31-34. 